\title{
Fricciones entre las ramas del poder público a propósito de la función pública en Colombia
}

\author{
Friction between the Branches of Government Regarding the Civil \\ Service in Colombia \\ Atritos entre os ramos do poder público a propósito da função pública \\ na Colômbia
}

\section{Germán Puentes GonZÁLeZ*}

FECHA DE RECEPCIÓN: 18 DE JUNIO DE 2015. FECHA DE ACEPTACIÓN: 31 DE MARZO DE 2016

DoI: http://dx.doi.org/10.12804/revistas.urosario.edu.co/sociojuridicos/a.5266

Puentes González, G. (2017). Fricciones entre las ramas del poder público a propósito de la función pública en Colombia. Estudios Socio-Jurídicos. 19(1), 79-123. Doi: http://dx.doi.org/10.12804/revistas.urosario.edu.co/sociojuridicos/a.5266

\section{RESUMEN}

La función pública es de vital importancia para el manejo de los asuntos del Estado y de la administración pública. Acogiendo la versión de Ramón Parada Vásquez, que precisa que la función pública debe entenderse como el conjunto de personas que investidas de unas atribuciones y competencias, cumplen unas determinadas funciones con el fin de prestar unos servicios públicos dentro de un marco jurídico en el cual deben desarrollar su actividad y responder por ella. El trabajo se divide en dos partes: la primera presenta la evolución del tema desde el momento en que se consolida el Estado-Nación colombiano hasta la Constitución Política de 1991, destacando los criterios, principios y valores que han presidido el tratamiento que se le ha dado al objeto en este estudio. En la segunda parte se da cuenta de las distintas lecturas e interpretaciones que las ramas del poder público le han dado a la Carta a propósito de la función pública y la carrera administrativa. Unas y otras se presentan en dos niveles de complejidad: en el primero, con la expedición de leyes y en el segundo, con la expedición de actos legislativos. Para evidenciar, en este contexto, las fricciones entre las ramas del poder público, se presentan las sentencias de la Corte Constitucional en defensa de la Carta Política, con las cuales sacó del ordenamiento jurídico disposiciones que pretendían violentar el texto Superior so pretexto de solucionar un problema de interinidad a miles de empleados públicos eludiendo el proceso de selección, mostrando así, una permanente fricción entre estas tres ramas del poder público. Al final, prevalecen las decisiones de la Corte Constitucional que, con su permanente pedagogía ha impulsado al Ejecutivo y al Legislatvio a trabajar de manera autónoma pero armónicamente como lo establece la Carta de 1991.

Palabras clave: función pública, carrera administrativa, ramas del poder público, concurso, mérito, patronazgo.

* Profesor e Investigador de la Universidad del Rosario, Facultad de Ciencia Política y Gobierno. Correo electrónico: german.puentes@urosario.edu.co 


\section{ABSTRACT}

The civil service is important for managing the affairs of the State and the public administration. According to Ramón Parada Vásquez, the civil service should be understood as the group of people who are vested with powers and competences, and fulfil certain functions in order to provide public services within the legal framework in which they must develop their activities and account for them. The present paper is twofold: first, it presents the evolution of the civil service from the time the Colombian nation-State is consolidated until the Political Constitution of 1991, outlining the criteria, principles and values that have been presided over the treatment being given to the purpose of this study. Second, the present text gives an account of several readings and interpretations that the branches of the government have been giving to the Charter with regard to the civil service and administrative career. Both will be available in two levels of complexity: the first, with the enactment of laws and the second, with the issuance of legislative acts. To demonstrate, in this context, the frictions between the branches of Government, the Constitutional Court's sentences in defense of the Cherter are presented, with which it takes out of the legal system law provisions intended to violate the Political Constitution; those provisions have been presented under the pretext of solving a problem of temporary character of thousands of public employees circumventing the selection process. For this reason, there has been a permanent friction among the three branches of government. In the end, the Constitutional Court's decisions have prevailed and with its permanent teaching it has prompted the Executive and the Legislative to work independently but harmoniously as it is established in the 1991 Constitution.

Keywords: Public service, public administration, branches of government, exam for public service, merit, patronage.

\section{RESUMO}

A função pública é de vital importância para a gestão dos assuntos do Estado e da Administração Pública. Acolhendo a versão de Ramón Parada Vásquez, determina que a função pública, deve-se entender como o conjunto de pessoas que conferidas de umas atribuições e competências, cumprem umas determinadas funções com o fim de prestar uns serviços públicos, dentro de um marco jurídico no qual devem desenvolver a sua atividade e responder por ela. $\mathrm{O}$ trabalho divide-se em duas partes: a primeira apresenta a evolução do tema desde o momento em que se consolida o Estado-Nação Colombiano até a Constituição Política de 1991, destacando os critérios, princípios e valores que tem presidido o tratamento que se lhe tem dado este objeto de estudo. Na segunda parte dáse conta das distintas leituras e interpretações que os Ramos do Poder Público lhe têm dado à Carta a propósito da função pública e a carreira administrativa. Umas e outras se apresentam em dois níveis de complexidade: no primeiro, com a expedição de leis e no segundo, com a expedição de atos legislativos. Como se tratara-se de polos opostos, do outro lado, se apresentam as sentencias da Corte Constitucional, em defensa da Carta Política, com as quais tirou do ordenamento jurídico disposições que pretendiam violentar o texto Superior sob pretexto de solucionar um problema de interinidade milhares de empregados públicos iludindo o processo de seleção, mostrando assim, uma permanente atrição entre estes três ramos do Poder Público. No fim prevalecem, as decisões da Corte Constitucional que, com a sua permanente pedagogia tem impulsado ao Executivo e ao Congresso a trabalhar de maneira autónoma, mas harmonicamente como o estabelece a Carta de 1991.

Palavras-chave: função pública, carreira administrativa, ramos do Poder Público, concurso, mérito, patrocínio. 


\section{Introducción}

El tema de la función pública ha estado en la agenda de los colombianos desde el comienzo del siglo xx pero ha carecido del apoyo armónico y decidido de parte de los responsables de su diseño e implantación para lograr un servicio civil robusto, ético y comprometido con los intereses nacionales. El exrector de la Universidad Nacional de Colombia, Moisés Wasserman (2015), opina que "sería moralizante tener una carrera pública dignificada, que promueva en su interior líderes y dirigentes que lleguen hasta el más alto nivel" ${ }^{\prime}$.

Este trabajo pretende mostrar dos aristas de la función pública²: de un lado resaltar la importancia histórica del hecho de haberse incluido con tanta fuerza en la Constitución de 1991, por cuanto es la primera vez que se constitucionalizan, con tanta claridad y precisión, sus principios rectores, dedicándole un capítulo en la Constitución Política ${ }^{3}$ - Para desarrollar este acápite, se echa mano de algunas nociones de función pública para explicar así su esencia, y se presentan las posturas asumidas por parte de las ramas del poder público y sus permanentes fricciones cuyas consecuencias retardan, desgastan y dificultan la conformación y consolidación de un servicio civil que haga posible desarrollar con eficiencia y eficacia las tareas encomendadas al Estado. Para abordar este tema y realizar el debate se recurre a un buen acervo de jurisprudencia de la Corte Constitucional, referida a la declaratoria de inexequibilidad

1 Con Wasserman (2015) se comparte la idea de que la profesionalización de la función pública es un aspecto esencial para lograr óptimos niveles de desempeño de los órganos y entidades del Estado en la búsqueda de la mejor asignación de los recursos para solventar los problemas de las comunidades y para lograr unas relaciones más confiables entre los ciudadanos y el Estado. La clave: los Recursos Humanos idóneos hacen la diferencia. En este trabajo se utilizan los vocablos servicio civil y función pública indistintamente.

2 La Función Pública puede entenderse desde varios puntos de vista: a) según Rodríguez (2002) "la expresión Función Pública, tomada en un sentido amplio, designa el conjunto de regímenes aplicables a la generalidad del personal de la administración" (p. 185); b) es la que nos presenta Parada (1995), donde se le da importancia a los Recursos Humanos, quien afirma que "con el término de función pública suele designarse tanto el conjunto de hombres a disposición del Estado que tienen a su cargo las funciones y servicios públicos, como el régimen jurídico a que están sometidos y la organización que les encuadra" (371). Esta definición será la utilizada en el presente trabajo.

3 Ver Titulo V Capítulo II de la Función Pública. 
de leyes y actos legislativos sobre el tema de la función pública y en ese marco lo atinente a la carrera administrativa.

Independientemente de la noción que se tenga de Estado, siempre se requerirá de un aparato administrativo para ejercer el gobierno. En concordancia con Richard Rose (1998) para el ejercicio del gobierno de una organización, y el Estado es una macro organización, se requieren al menos estos cinco elementos: 1. Reglas de juego que llamaremos: instituciones; 2 . Las organizaciones a través de las cuales se ejerce el poder y el gobierno; 3. Los programas ejecutados por las organizaciones que en el fondo son las políticas públicas; 4. Los recursos financieros, y 5. Las personas con quienes se pueden llevar a cabo todas las acciones encomendadas al Estado (pp. 68-70).

El quinto elemento, es decir, las personas organizadas en el sentido expuesto por Parada (1995) - antes mencionado- constituye el centro de nuestra atención. ¿Desde cuándo el servicio civil o la función pública han sido de interés para los colombianos y por qué razones?, ¿qué tratamiento le han dado las instancias de gobierno y demás ramas del poder público?, ¿cómo las distintas posturas de los órganos del poder público han afectado la conformación y consolidación de un cuerpo funcionarial al servicio de los intereses generales?

La hipótesis que se plantea es la siguiente: el desarrollo del tema de la función pública, en buena parte de la historia de Colombia, se hizo con criterios eminentemente jerarquizados, clientelares y de patronazgo y solo recientemente, por un proceso de toma de conciencia aún sin terminar, inspirado por referentes externos, se ha presentado una mutación que posibilita comprenderlo y tramitarlo con criterios de racionalidad y de ética pública más acordes con los tiempos modernos.

Lo referente a la presencia del patronazgo, el manejo clientelar de la función pública y su jerarquización, responde según algunos autores ${ }^{4}$ a las instituciones que desde la época de la conquista y luego en la colonia impusieron los españoles, como la encomienda: el poder concentrado en

4 Sobre el impacto de las instituciones en la vida de la personas y de las sociedades, Robinson James y Acemoglu Daron, en Por qué Fracasan los países (2012) defienden la tesis de que aunque las instituciones económicas sean críticas para establecer si un país es pobre o próspero, son la política y las instituciones políticas las que determinan las instituciones económicas que tiene un país. 
una persona o en una élite que todo lo puede y todo lo decide. Es claro que las instituciones influyen poderosamente en la vida de las personas, definiéndoles el rumbo y por ende el de la sociedad. Las instituciones impuestas se quedaron en el alma de la nación mestiza y aún hoy, después de casi doscientos años de la proclamación de la independencia, se sigue practicando el clientelismo, el patronazgo, la jerarquización y la imposición de actos de autoridad para gobernar y dirigir las entidades del gobierno en detrimento del mérito como criterio del reclutamiento y selección del funcionariado público.

Como ya se dijo antes, este trabajo contiene dos partes: en la primera se hacen algunas reflexiones sobre la importancia histórica de haber incluido en la Carta el tema de la función pública como esencial en las administraciones $\mathrm{y}$, en la segunda parte, se desarrolla a profundidad el tema de las posturas, fricciones y controversias de las decisiones adoptadas por las ramas del poder público y se hace un debate sobre sus consecuencias.

\section{La burocracia como factor político}

La burocracia pública es el alma y nervio requeridos para que el gobierno, como máxima expresión del Estado, pueda cumplir con sus grandes objetivos y propósitos a través de los órganos y entidades que lo conforman.

En este trabajo se entenderá la burocracia y al funcionario público en el sentido que lo expone el padre de la sociología. Weber (1985) plantea que

La ocupación de un cargo es una profesión. Esto es obvio, primero, en la exigencia de un curso de preparación estrictamente fijado, el cual reclama la plena capacidad de trabajo, durante un largo periodo, y en las pruebas especificas que son un requisito previo para el empleo (p. 15).

Esta visión contempla elementos que, en tiempos más recientes, se privilegian y se exigen al momento de asumir empleos o cargos públicos en nuestro país. 
Como se verá más adelante, estos elementos son la manzana de la discordia y los motivos que explican la fricción reiterada entre el Legislativo y el Ejecutivo por una parte y, la Corte Constitucional, por la otra. Los primeros, contrariando el significado de la función pública a través de leyes y actos legislativos, pretenden establecer una relación de dependencia y subyugación entre la parte política del Estado - los elegidos-y los nombrados, igual que sucedía en la época feudal. Al respecto, Weber (1985) afirma que: "Al menos en el Estado moderno desarrollado, el funcionario político no es visto como el servidor personal de un gobernante" (p. 16).

Por otra parte, la Corte Constitucional, en su rol de guardiana de la Constitución, saca del ordenamiento jurídico leyes y actos legislativos que pretenden desconocer y violentar los principios y criterios consagrados en la Carta acerca de cómo se debe tramitar el tema de la función pública y de la carrera administrativa. Esta permanente controversia de puntos de vista opuestos y sus consecuencias son presentadas y analizadas en las páginas siguientes.

El gobierno, en sentido restringido y de acuerdo con la ley de estructura y funcionamiento del Estado, está conformado por la rama ejecutiva del poder público ${ }^{5}$.

Pero por razón de su misión, en todas las organizaciones de las otras ramas del poder público hay una parte normativa que orienta su quehacer: unos procesos que cumplir, unos presupuestos que ejecutar, unas políticas públicas que desarrollar; todo lo anterior se hace con personas y para que los resultados sean racionales, eficientes y ecuánimes frente a los usuarios, se requiere de una función pública formada, organizada, capacitada y gestionada en un marco de principios y valores acordados y estipulados en el Pacto Social, que aglutina la voluntad de los asociados, es decir de la Nación entera.

Pero tal como se dijo más arriba, las costumbres, hábitos y tradiciones que heredamos de los españoles durante los años de la conquista y la colonia, suplantaron y destruyeron las costumbres, hábitos y tradiciones de los nativos o aborígenes para implantar a su vez una escala de valores, 
principios y cosmovisiones foráneos sobre la manera como debía organizarse la sociedad durante el tiempo en que duró su poder hegemónico desde 1492 hasta la independencia en 1819. Siguiendo a Pomer (2004) a propósito de la herencia colonial,

la corriente humana que arribó fue la Espuma de España: ladrones marcados a hierro, vagabundos y bandidos y deudores que procuraban escapar de ávidos acreedores (...) las Indias, refugio y protección de todos los desesperados de España (...) las Indias, salvo conducto de homicidas (p. 56).

Estas y otras herencias señaladas a continuación suplantaron las costumbres de los nativos que, por perversas que hubieran sido, eran fruto del desarrollo natural y tranquilo de estas comunidades y no el resultado de amalgamamientos de conductas asumidas durante siglos de lucha entre moros y aborígenes de la península Ibérica. El sociólogo Juan Agustín García (citado por Pomer 2004) considera que en la época de la colonia,

la ley fue la voluntad del patrón, y el primer deber la fidelidad (...) otra herencia poco estimable es la avaricia, el espíritu de los negocios, la preocupación de la fortuna; pero no la ordinaria y común, que más o menos se observa en todas partes; era una ambición de riqueza que no dejaba entrar otros móviles nobles y civilizados, que actúan armónicamente en los pueblos bien constituidos (p. 62).

La función pública, por su naturaleza de poder y privilegio para quienes la ejercen en nuestro medio, ha estado guiada por ese paradigma heredado que parece estar distante de un modelo de gestión de los asuntos públicos donde lo colectivo, lo de todos, está al servicio de los intereses generales.

Después de la independencia y durante el resto del siglo XIX hasta la constitución de 1886, el tema de la función pública o del servicio civil careció de los grandes debates que se dieron en otras latitudes como Estados Unidos de Norte América ${ }^{6}$ y Europa. En la Colombia naciente, las

6 En la segunda mitad del siglo XIX el tema de la Administración Pública en Estados Unidos de Norteamérica estaba candente y se planteaba que la modernización del Estado debía abarcar 
preocupaciones eran otras, como la consolidación de la independencia, de la nación y de las formas de gobierno. Quienes se alzaban con el poder, organizaban el gobierno con alto grado de discrecionalidad, poco o ningún control social y alto déficit de responsabilidad social al momento de rendir cuentas. Lo opuesto a este panorama es relativamente reciente en nuestra vida republicana.

En la Constitución de 1886 el tema de la función pública estuvo ausente de las preocupaciones de quienes pensaron y redactaron la Carta. Solo hasta los primeros años de 1900 se empezó a tomar conciencia del tema como consecuencia de la visión, propuestas y debates adelantados por Rafael Uribe Uribe. Hoy, después de más de cien años, su pensamiento y su filosofía, las razones y motivos esgrimidos en la exposición de los proyectos de ley presentados por aquella época al Congreso para conformar una suerte de cuerpo élite debidamente formado en los valores y principios éticos y morales, y capacitado en los asuntos técnicos, están vigentes.

Rafael Uribe fue partidario de un Estado moderno con un servicio civil formado para el oficio público, instruido en los asuntos de la administración pública, en el decoro y la urbanidad que deben poseer los empleados y funcionarios frente a los caudales y demás recursos del Estado, incluido el manejo de la autoridad y el poder público. Tales empleados públicos deben tener como cualidades esenciales carácter, habilidad técnica, honradez y buenos antecedentes que los pongan en circunstancias excepcionales de desempeño para que desde los cargos que ocupen, den muestra permanente de ser la mejor opción frene a cualquier otro ciudadano. Las siguientes son algunas ideas expuestas por quien más tarde pasaría a la historia de Colombia con el nombre de "Apóstol, Paladín y Martir"7 y que han servido de permanente referente en los debates sobre

claramente tres componentes: las organizaciones, los métodos de trabajo y el personal civil. Sobre éste último punto Woodrow Wilson citado por Shafritz y Abert (1999) se preguntaba si en los temas de administración pública se habrá cumplido cuando se ha enseñado a la gente cuál tipo de administración debe desear, exigir y cómo obtener lo que exige (pp. 90-92).

7 Rafael Víctor Zenón Uribe Uribe nació en Valparaíso -Estado Soberano de Antioquiael 12 de abril de 1859 y murió asesinado en las escalinatas del Capitolio el 16 octubre de 1914. Además de abogado rosarista, diplomático y profesor, fue ante todo un líder militar y político; una de las grandes figuras de la vida nacional de finales del siglo XIX y principios del XX; un mártir de la intolerancia política, sacrificado en aras de sus ideales políticos. 
el tema de la función pública. Estas ideas son tomadas de la conferencia leída ante la Unión Nacional de Industriales y Obreros y ante el Ministro de Instrucción Pública el 4 de diciembre de 1910 en el Salón de Grados:

El Problema de la tenencia de los empleos. Hace falta una ley general de funcionarios públicos que fije las condiciones comunes de su nominación, promoción, dimisión, remoción, jubilación [...] ¿De qué sirve que un funcionario sea competente si no tiene la seguridad de permanecer en su empleo, de suerte que cuando haya puesto en vía de ejecución medidas que cree útiles, viene el sucesor y las interrumpe o las cambia? ¿Ni cómo ser competente si no se le escoge por su propio valer, sino por razones de parentesco, o de favoritismo? La política de clientela es el resultado inevitable de una organización administrativa que para nada o para muy poco tienen en la cuenta formación de especialistas [...] las designaciones hechas con ese criterio son contrarias al espíritu de las instituciones democráticas, pues para que haya verdadera democracia se requiere que los funcionarios sean servidores del público que los paga. Si solo lo son de unos pocos personajes o de un grupo, habrá caciquismo, habrá oligarquía, todo, menos democracia. La elección de los empleados, sea hecha por quien fuere y por el sistema que fuere, debe recaer en aquellos ciudadanos que tengan competencia para el puesto, es decir, carácter, habilidad técnica, experiencia, honradez, posición social, y buenos antecedentes que los coloquen en posición de servir mejor que cualquier otro el cargo de que se trate. El gobierno que rehúse o arrebate el empleo a un ciudadano dotado de estas prendas y lo entregue a otro que carezca de ellas, será siempre -llámese como se llamare- un detestable gobierno, porque de cualquier cosa podrá jactarse, menos de administrar rectamente los intereses del pueblo; y porque contraponer los intereses especiales a los intereses públicos, de suerte que en el conflicto triunfen los primeros sobre los segundos, es volver contra el pueblo las funciones que él ha confiado y paga para que se le sirva.

[...]

Hay que fundar carreras: la diplomática, la consular, la judicial, la militar, la docente o del profesorado, y otras por el estilo, como único medio de estimular el estudio, la honradez y el celo y formar verdaderos servidores de la patria. Valen infinitamente más pocos empleados, idóneos y bien retribuidos, que muchos mediocres y mal pagados. (Instituto Colombiano de Cultura 1973, pp. 132-133). 
De los apartes de la conferencia de Uribe Uribe se resaltan algunos aspectos de los cuales carecía la sociedad, el Estado y la administración pública a principios del siglo Xx. Tales aspectos, aún hoy, no se han podido solventar como las reglas claras y transparentes para la selección del personal; los méritos que deben tener los candidatos; la estabilidad en el empleo para quienes demuestren ser eficientes, eficaces y estar actualizados en la utilización de las tecnologías; la prevalencia del interés general sobre el particular, de grupo o de partido. Estos aspectos aún se siguen discutiendo y decantando cien años después de los debates del caudillo de marras.

\section{Ley 165 de 1938}

Pasaron varias décadas y en 1938 el Congreso se apropió del tema y expidió la Ley 165 de aquel año, "por la cual se crea la carrera administrativa". Norma que tuvo un precario desarrollo y aplicación. Mientras tanto las prácticas del spoil system ${ }^{8}$ seguían orientando el manejo de la función pública en cuanto a las condiciones y requisitos que debían reunirse para acceder y mantenerse en los cargos públicos.

Fue con la llegada del Frente Nacional ${ }^{9}$ que cambió un poco el asunto en cuanto al manejo de la burocracia al servicio de las administraciones públicas tanto nacional como territoriales, por cuanto el pacto era que en virtud de la alternancia de los dos partidos tradicionales -liberal y conservador - en el gobierno, el partido que estaba de turno ejerciendo el poder debía, por mandato de la Constitución, recibir la colaboración del otro y en materia de la burocracia, el pacto afirmaba que los funcionarios que tenían la facultad de nombrar y remover empleados administrativos, no podían ejercerla sino dentro de las normas que expidiera el Congreso

8 En este trabajo se entiende por spoil system la teoría y la praxis del despojo, es decir, en las contiendas electorales quien gana el poder político gana también la posibilidad de gobernar.

9 El Frete Nacional fue el periodo de la historia de Colombia (1958-1974) en el que se alternó el gobierno entre liberales y conservadores con el propósito de poner fin a una suerte de guerra civil no declarada en la cual se mataban liberales y conservadores hasta por motivos que hoy se consideran triviales como vestirse con prendas de determinado color. Hay sentimientos que con el paso del tiempo se arraigan más profundamente en el alma de quienes los prohíjan y están dispuestos a dar la vida por ellos fácilmente. Entre tales sentimientos están los deportivos, políticos y religiosos. Y, en parte, eso fue lo que sucedió en ese periodo. 
para establecer y regular las condiciones de acceso al servicio público, de ascenso por mérito y antigüedad ${ }^{10}$.

Por otra parte, el parágrafo del artículo 120 de la Constitución de 1886 después de la enmienda del plebiscito del 1 de diciembre de 1957 y del Acto Legislativo 1 de 1968, establecía que

los Ministros del Despacho serán de libre nombramiento y remoción del Presidente de la República, pero la paridad de los partidos liberal y conservador en los Ministerios, Gobernaciones, las Alcaldías y los demás cargos de la Administración que no pertenezcan a la Carrera Administrativa se mantendrá hasta el 7 de agosto de 1978.

Igualmente se estipuló que, con el ánimo de preservar el espíritu nacional en la conformación de la rama ejecutiva y de la administración en general, el partido ganador en las contiendas haría los nombramientos dándole participación adecuada y equitativa al partido mayoritario dentro de las minorías.

En todos estos años, desde 1938 cuando se expidió la primera ley de carrera administrativa hasta 1991 cuando se expide la Carta hoy vigente, el tema de la función pública careció de gran protagonismo ante el Consejo de Estado, y entre esta Corporación y el Ejecutivo. Entre las razones que explican esta situación, entre otras, se pueden mencionar la poca aplicación y desarrollo de las normas; escasos procesos de concursos públicos para seleccionar a empleados y funcionarios y, ante todo, el interés de los partidos políticos, de los empleados interinos (entiéndase provisionales) y el mismo gobierno de no tramitar el tema de acuerdo con el derecho y más bien echar por el desecho, en el sentido de permitir de tiempo en tiempo, el ingreso a la carrera administrativa vía inscripción extraordinaria, obviando los concursos públicos, frustrando las expectativas de quienes veían en el sector público una opción laboral, deteriorando además la imagen del Estado y la majestad del empleo público. En resumen, se practicó lo que hemos llamado en otros escritos la ventanilla siniestra para ingresar a la función pública (Puentes, 2004, p. 75).

10 Las instituciones o reglas de juego vigentes antes de la Constitución de 1991 sobre función pública se encuentran en el artículo 62 de la Carta Política de 1886, el artículo $5^{\circ}$ del Plebiscito de 1957 y el parágrafo del artículo 120. 


\section{Nuevas instituciones en la Constitución de 1991 a propósito de la función pública}

El tema de la función pública está desarrollado en el Capítulo II del Título V de la Carta de 1991. Allí se estipuló que no habrá empleo público ${ }^{11}$ que no tenga funciones detalladas en la Constitución, la Ley o el reglamento. Esta caracterización es consecuente con la noción de función pública expuesta por el profesor Ramón Parada Vásquez (2004), anteriormente citada, en el sentido de que tales funciones constituyen los mandatos de lo que se puede hacer y no hacer desde el empleo público, es decir, constituyen el marco jurídico dentro del cual se ejerce la función pública.

A propósito de los servidores públicos, se optó por establecer que, en su conjunto constituyen una suerte de género dentro del cual existen tres especies así: a) los miembros de las corporaciones públicas (congresistas, diputados, concejales y ediles); b) los empleados del Estado y de sus entidades descentralizadas territorialmente y por servicios, quienes en su mayoría son los nombrados por los elegidos, y c) los trabajadores del Estado quienes se vinculan a través de un contrato de trabajo y prestan su concurso en las empresas industriales y comerciales del Estado o en las sociedades de economía mixta y se les aplica el mismo régimen de las industriales y comerciales.

Los empleados públicos conforman la típica función pública, pues de acuerdo con Olías de Lima (1995) su vinculación es a través de un

contrato de lealtad, típico de las organizaciones públicas, en el que el trabajador pone a disposición de su patrono unas capacidades profesionales, recibe instrucciones imprecisas que debe completar con su pericia o su conocimiento del contexto, las especificaciones del trabajo

1 La noción de empleo público, en nuestra legislación y sin ir tan lejos, se remonta a 1968 cuando se expidió el Decreto de Ley 2400 de aquel año y se precisó que: “Se entiende por empleo el conjunto de funciones señaladas por la Constitución, la Ley, el reglamento o asignadas por autoridad competente que deben ser atendidas por una persona natural". Esta versión es la fuente de inspiración para el Ejecutivo y para el Congreso cuando han querido referirse al tema. Se sugiere ver, adicionalmente, las siguientes disposiciones: Decreto de Ley 1042/78 artículo 2; Ley 909/94 artículo 19. 
o de los objetivos pueden ser cambiadas en cualquier momento y el desempeño solo puede ser evaluado en términos de lo que cada uno aporta a la organización (p. 23).

En este concepto hay al menos dos expresiones que no concuerdan con la legislación colombiana. La primera es que se habla de "contrato" para los empleados públicos, cuestión que en nuestro caso es inapropiado, pues para ello se utiliza el nombramiento y la posesión como única forma válida de vinculación al servicio público $y$, la segunda es que se refieren al "trabajador" pues para nuestro caso es el empleado.

De lo anteriormente dicho se desprende, claramente una primera conclusión: el tema de la función pública ha sido objeto de permanente preocupación en los distintos momentos de la historia de Colombia; unas veces se tramitó a través de leyes y otras más recientes, incluyéndolo en la Constitución y luego desarrollándolo por la vía de la legislación ordinaria o extraordinaria. A pesar de reconocer importancia al tema, la dificultad ha residido en que por un lado van las normas y por otro la praxis administrativa como se verá a continuación.

\section{Las fricciones entre las ramas del poder público a propósito de la función pública}

A continuación se presentan cinco trascendentales eventos durante la vigencia de la Carta de 1991, en los cuales se muestra claramente la actitud de las ramas del poder público a propósito del tratamiento que, cada una de ellas, le ha querido dar al tema de la función pública.

Tomando prestado el vocablo de la física, la fricción para este trabajo se entiende como sinónimo de fuerza que se encarga de reducir o frenar el avance de un proceso. En este caso tal proceso apunta a conformar el servicio civil en Colombia soportado en el mérito previamente comprobado. Si bien es cierto que esta idea no es nueva en nuestro ordenamiento, sí fue reforzada en el Pacto Político de 1991, que generó un cambio en las expectativas frente a la burocracia en el sentido weberiano. 
Las situaciones analizadas a continuación ponen en evidencia las fricciones de las fuerzas que desataron las ramas del poder público, a propósito de la conformación de la carrera administrativa meritocrática.

Por regla general, los empleos en la función pública son de carrera. Así lo dispuso la Asamblea Nacional Constituyente (Gaceta Constitucional 113, 1991, p. 8), y así quedó consagrado en el artículo 125 de la Carta de 1991 cuyo tenor es: "los empleos en los órganos y entidades del Estado son de carrera". Hay excepciones al mandato anterior y son los empleos de elección popular; los trabajadores oficiales y, los de libre nombramiento y remoción que, de manera excepcional, determine la ley.

¿Dónde están las supuestas fricciones y entre quienes se presentan? El Congreso de la República al expedir la Ley 27/9212 exceptuó de la aplicación del principio de carrera administrativa a buena parte de los empleos de la función pública del nivel territorial, contraviniendo el mandato constitucional antes mencionado, con lo cual el Congreso con su decisión invirtió el sentido del principio y lo que era excepción lo quiso convertir en regla, violentando con ello el espíritu de la Constitución. Con tal actuación el Congreso deja entrever una clara influencia de miembros de la rama ejecutiva -léase director de la función pública, gobernadores y alcaldes- quienes todavía sienten un gran entusiasmo cuando se trata de vincular y desvincular de los cargos públicos a las personas que ellos quieran, en una franca demostración de clientelismo político, patronazgo, caciquismo y spoil system.

Un segundo elemento aún más protuberante que el anterior hace todavía más notoria la fricción entre las ramas del poder público en materia de función pública. Se refiere al hecho de que por ningún motivo, según la Constitución de 1991, se puede excepcionar de la aplicación de la carrera administrativa, sin contravenir la Carta, a la totalidad de los empleos de alguna entidad del Estado pretextando razones de seguridad o de especial sensibilidad para el ejercicio de ciertas funciones públicas. Pues bien, tal como se establece en la Ley 61/8713, ratificada por la Ley

12 Con esta ley se aplicó por primera vez y de manera efectiva la institución de carrera administrativa en el nivel territorial, después haberse dicho en la Ley 165/38 y luego en el decreto $1732 / 60$ que la carrera se aplicaría a nivel nacional.

13 En el caso de la Ley 61/87 es entendible que se hubiera exceptuado de la aplicación de las normas de carrera de manera total a las entidades allí relacionadas, so pretexto de que 
27/92 en su artículo segundo, se declaran de libre nombramiento y remoción a la totalidad de la planta de cargos de ciertas entidades en abierta contradicción del principio rector de la Constitución que prescribe que los empleos en el sector público, por regla general, son de carrera administrativa. Las entidades que se excluyen de aplicar el principio de carrera son entre otras las siguientes: la Presidencia de la República; la Dirección General de Aduanas y la Dirección General de Impuestos; los empleados de tiempo parcial; los empleados públicos del Ministerio de Defensa y la Policía Nacional, y los empleados públicos de las empresas industriales y comerciales del Estado, por citar algunos ejemplos.

Es claro, entonces, que en el primer evento se trató de reducir la carrera administrativa a los empleos inferiores, de bajo rango, cuya actividad profesional implica la aplicación de energías más de carácter físico que intelectuales ${ }^{14} \mathrm{y}$, en el segundo evento se trató de excluir de la aplicación de la carrera administrativa a colectivos enteros como los ya citados. En uno y otro evento se legisló en contravía de lo estipulado por la Constitución.

\section{El mérito como principio rector para el ingreso a los empleos de carrera administrativa. El primero es el primero}

La Carta de 1991 establece en el artículo 125 que "El ingreso a los cargos de carrera y el ascenso en los mismos, se harán previo cumplimiento de los requisitos y condiciones que fije la ley para determinar los méritos y calidades de los aspirantes". Este procedimiento de verificación de la idoneidad moral y técnica de los aspirantes se compone de varias etapas que van desde la convocatoria, reclutamiento, aplicación de pruebas y elaboración de las listas de quienes aprobaron las pruebas en estricto orden de puntaje y periodo de prueba.

se trataba de entidades cuya naturaleza era demasiado sensible para los intereses del Estado en general y para el Ejecutivo en particular. Pero ante la vigencia del artículo 125 de la Constitución de 1991, que dispone que por regla general los empleos en el sector público son de carrera, es clara al inexequibilidad sobreviniente de la Ley 61/87 y del artículo segundo de la Ley 27/92. (Ver sentencias C-391/93, C356/94, C-306/95, C-159 y C-408/97).

14 Según la naturaleza de las funciones, las competencias y requisitos para su desempeño, los empleos se clasifican en cinco niveles administrativos: Directivo, Asesor, Profesional, Técnico y Asistencial. Para mayor detalle se puede consultar el Decreto de Ley 770/2005. 
El concurso consiste, entonces, en abrir las compuertas de la función pública o servicio civil para todos aquellos que queriendo prestar sus servicios a la sociedad a través del servicio público, puedan demostrar sus competencias técnicas y sus calidades morales y éticas. El proceso de selección debe incluir la totalidad de los aspectos a evaluar a los participantes. Para facilitar este asunto se debe tener en cuenta el perfil del cargo, es decir, los aspectos intrínsecos y extrínsecos del cargo a proveer, más ciertas características que deben reunir los candidatos; pero todo lo que se precisa examinar y evaluar debe aplicársele a todos los candidatos por igual, de suerte que una vez conformada la lista con quienes aprobaron las pruebas, al nominador solo le queda producir el nombramiento en cabeza del primero de la lista, ya que fue el que demostró contar con las mejores aptitudes.

No obstante lo anterior, el Congreso en reiteradas ocasiones legisló de tal suerte que el nominador quedara con la absoluta libertad de nombrar en algunos casos a uno de quienes ocuparan los cinco primeros puestos en el ranking de aprobados, como lo estipuló la Ley 270 de 1996, Estatuto de la Administración de Justicia. En otros casos, en virtud de facultades extraordinarias, el Ejecutivo expidió el decreto 1222/93 y estableció que el nombramiento al final del proceso de selección podía recaer en uno de los tres primeros que conformaran la lista de elegibles (léase nombrables), según discrecionalidad del nominador apartándose así, de manera ostensible, de lo ordenado por la Constitución en el artículo 125. Así se reitera a través del Decreto 256/94 por el cual se reglamenta el Decreto 1222/93 en cuyo artículo 3 establecía el orden para proveer las vacantes definitivas de cargos de carrera administrativa. La Ley 270/ 96 Estatuto de la Administración de Justicia, en el artículo 166 referido a la carrera, establecía la lista de candidatos para proveer vacantes definitivas en cargos de carrera así: La provisión de cargos se hará de listas superiores a cinco (5) candidatos con inscripción vigente en el registro de elegibles y que para cada caso envíen las Salas Administrativas del Consejo Superior o Seccionales de la Judicatura.

Así las cosas, es evidente que en la mayoría de las ocasiones quién obtenía el mejor puntaje perdía porque casi nunca se nombraba al primero por las presiones que ejercían los que estaban dentro de los cinco o dentro de los tres primeros por considerar que ellos también tenían 
derecho a ser nombrados $y$, en consecuencia pretextando razones de distinta índole, presionaban la voluntad del nominador.

Con estos dos hechos, uno del Ejecutivo con el Decreto 1222/93 expedido en virtud de facultades extraordinarias y el otro del Congreso con la Ley 270/96, se violenta flagrantemente el artículo 125 de la Constitución Política tal como lo dijo la Corte Constitucional en sentencias citadas más adelante, a través de las cuales declaró la inexequibilidad de tales disposiciones. Lo que es claro es que tanto el Ejecutivo como el Legislativo conocen, como los que más, el tenor de la Carta pero se resisten a enrutarse por la senda de la meritocracia. No obstante que para las fechas de expedición de las disposiciones citadas, la Corte Constitucional ya había proferido sentencias declarando inexequible leyes que iban en contravía del espíritu de la Constitución en materia de carrera administrativa y de la meritocracia.

\section{Actuación de la Corte Constitucional a propósito del principio del mérito}

Hubo entonces necesidad de recurrir ante la guardiana de la Constitución para que nuevamente corrigiera los desvíos en los que incurrieron las otras dos ramas del poder público, y continuara con su labor de hacer pedagogía sobre la manera como debe entenderse y tramitarse el tema referido a los empleos que conforman la carrera administrativa y el procedimiento para acceder a ellos.

En reiteradas sentencias la Corte Constitucional precisó:

Esta Corporación ha venido conociendo de múltiples procesos de tutela en los que los accionantes se quejan de haber concursado para ingresar a un cargo de carrera administrativa y, a pesar de haber obtenido un puntaje superior al de quien en últimas se nombró, fueron excluidos con el argumento de la falta de idoneidad moral o social de los concursantes, exclusión que de no estar plenamente justificada se convierte en arbitraria (C-040/1995).

Normalmente las razones expuestas por los nominadores que procedían así, era que el proceso de selección no contemplaba ciertos aspectos considerados críticos y que el nombrado por ellos sí reunía la totalidad de requisitos y condiciones que se debían exigir para el cargo a proveer. 
Ante tal situación lo que se presentaba era el mismo manzanillismo, clientelismo o cacicazgo de antes, desvirtuando de esta manera el espíritu de la carrera administrativa cuyo texto se convertía en letra muerta.

Para obviar tal situación y lograr que el texto de la Constitución tuviera plena aplicación la Corte Constitucional resolvió muchas tutelas a favor de demandantes y sentenció:

cual fuere el método o sistema elegido, éste debe contener criterios específicos y concretos para efectuar una selección en la que aparezcan como valores dominantes la capacidad profesional o técnica del aspirante, sus calidades personales y su idoneidad moral, acordes con las funciones del empleo y las necesidades del servicio público. Por tanto, no puede quedar al nominador una libertad absoluta para que designe a su arbitrio, pues, el nombramiento siempre tendrá que recaer en quien haya obtenido el mayor número de puntos (C-41/1995).

El hecho de que los nominadores puedan nombrar a discreción uno de los tres primeros o uno de los cinco primeros de la lista conformada por quienes superaron todas las pruebas es convertir unos empleos de carrera administrativa en empleos de libre nombramiento y remoción por el mero arbitrio del nominador. Con lo anterior se desvirtuaba el principio del mérito y se defraudaba la confianza de los demás aspirantes que compitieron en franca lid y al ganar el concurso con un mejor puntaje de aquel en que recaía el nombramiento, el proceso de selección perdía su virtud, pues se incurría en la paradoja de que quien ganaba el concurso lo perdía porque nunca lo nombraban. Además de la violación al artículo 125 de la Constitución Política, también se violaba el principio de la buena fe contenido en el 83 Superior.

En resumen, después de decenas de tutelas y demandas de revisión de constitucionalidad va quedando claro, aunque no seguro, que el proceso de selección debe incluir todos los aspectos a ser evaluados según el perfil del cargo a proveer, y quien obtiene el máximo puntaje y encabeza la lista de los examinados tiene derecho a ser nombrado y posesionado para el cargo que concursó, siempre que cumpla los demás requisitos necesarios para tomar posesión del mismo. Un proceso transparente con garantías para todos los aspirantes, con igualdad de condiciones en la competencia, conducirá a seleccionar al mejor calificado para el mejor empleo. 


\section{No hay inscripción extraordinaria}

Uno de los lastres más perversos y difíciles de erradicar del ámbito de la función pública o del servicio civil ha sido la permanente presión del Ejecutivo y del Legislativo para vincular a su clientela utilizando la vía de la inscripción extraordinaria en el sistema de carrera administrativa. Se afirma que es perverso, y sin lugar a dudas es así, por cuanto atenta contra varios principios rectores y valores que presiden la función pública, entre ellos el del mérito cuya esencia es la selección de los mejores; el de la igualdad que pretende que todos los aspirantes a ocupar un cargo público de carrera sean tratados en el proceso de selección en condiciones de igualdad; el proceso concursal no solo es violentado sino que desaparece por cuanto con esta práctica se inscribe "automáticamente" a quienes están interinamente desempeñando los cargos de carrera mientras se adelanta el proceso de selección a través del concurso público. En esta situación no hay evaluación de los méritos, es decir, la idoneidad técnica y moral; por el contrario, de lo que se trata es de inscribir a quien llegó primero al empleo y no al mejor para dicho cargo, con lo cual también se violenta otro derecho que tienen todos los ciudadanos como es el de participar en la conformación, ejercicio y control del poder político. Se priva a la sociedad de la posibilidad de seleccionar a los mejores elementos dentro de sus miembros para ponerlos a su servicio; se envilece la imagen del Estado, del servicio y del servidor público; se entroniza la práctica del padrinazgo, de la clientela política y del cacicazgo; se crean y se recrean escenarios protervos para hacer política en los cuales se intercambian puestos por apoyos y lealtades políticas, con el uso abusivo del presupuesto público que nos pertenece a todos, al igual que la función pública.

¿Dónde se presenta la fricción de las ramas del poder público en este subaspecto? En varios momentos y con los argumentos más oportunistas y, aparentemente, pragmáticos ante el estupor de los que no tienen voz. El Congreso y el Ejecutivo han querido resolver el problema de sus clientelas políticas ordenando y ejecutando procesos conducentes a verificar los requisitos a quienes, en los distintos momentos de expedir las leyes en esta materia, estaban vinculados de manera provisional, es decir, mientras se efectúan los concursos. Obvio es que si los nominadores 
han actuado de acuerdo con las normas (que no siempre sucede) para vincular en los cargos públicos a determinadas personas, ellas llenarán los requisitos al momento de la verificación.

Cuando se ha ordenado la inscripción extraordinaria siempre se ha ido a contrapelo del principio de la igualdad consagrado en la Norma de normas. Como el ingreso a los empleos de carrera administrativa requiere concurso de méritos, al posibilitar el ingreso e inscripción extraordinaria a tales empleos, se trata entonces, según las leyes que a la postre fueron declaradas inexequibles, de verificar los requisitos formales de quienes estuvieren vinculados en los empleos de carrera en condición de provisionales. De esta manera se declara tácitamente innecesario el concurso de méritos para ingresar a la carrera administrativa.

Pero la arbitrariedad del Congreso y del Ejecutivo va aún más allá, es decir, si algunos de los empleados vinculados provisionalmente en cargos de carrera administrativa, al momento de expedirse la norma no llenan los requisitos para desempeñar los cargos que ostentan, se les conceden plazos adicionales para que cumplan los requisitos, sin que, frente a las irregularidades presentadas por haber nombrado y posesionado a personas que no cumplían los requisitos y condiciones para asumir los cargos públicos, los organismos de control hayan encontrado irregularidad alguna.

Ante la situación anteriormente expuesta se ve claramente el concurso de las distintas entidades del Estado, incluyendo las de Control que no glosaron los pagos, teniendo facultad para ello, a favor de la politiquería y en defensa de su cauda política representada en personas vinculadas al servicio público sin el cumplimiento de los requisitos establecidos en los manuales de funciones de las entidades públicas. Es la utilización de las instituciones y de las organizaciones para dar cumplimiento a intereses protervos en detrimento del supremo interés general de la sociedad y del derecho a contar con una burocracia oficial competente, honesta y comprometida. Veamos los casos:

\section{La Ley 61/87}

Esta ley, a propósito de la inscripción extraordinaria, es decir, sin concurso en la carrera administrativa de los empleados interinos o provisionales, estableció en los artículos 5 y 6 lo siguiente: 
Artículo $5^{\circ} \mathrm{Al}$ entrar en vigencia esta Ley, los empleados que estén desempeñando un cargo de Carrera sin que se encuentren inscritos en la misma, deberán acreditar, dentro del año inmediatamente siguiente, el cumplimiento de los requisitos señalados para sus respectivos empleos en el manual de requisitos expedido por el Gobierno Nacional(...)

Artículo $6^{\circ}$. Los empleados que no acrediten poseer los requisitos para el desempeño del cargo, dentro de los términos señalados en el artículo anterior, quedarán como de libre nombramiento y remoción pero si continúan al servicio del mismo organismo sin solución de continuidad podrán solicitar su inscripción en la carrera cuando demuestren poseer los requisitos para el cargo que están desempeñando en el momento en que acrediten dicho cumplimiento.

Sin embargo, los empleados que tengan cinco o más años de servicio a la entidad, tendrán derecho a solicitar su inscripción en la carrera siempre que para el ejercicio de las funciones del empleo que desempeñan no se exija título profesional correspondiente a una carrera reglamentada.

Para esta época existía algún déficit de conciencia en cuanto a la institución de la carrera administrativa, pues como ya se ha dicho, en la Constitución de $1886^{15}$ el tema tuvo bajo perfil y la Corte Suprema de Justicia con su Sala Constitucional, durante años, no fue sensibilizada sobre el tema y solo con la refundación del Estado con la Carta de 1991, el tema de la función pública y la carrera administrativa ganaron el estatus que cambió radicalmente con relación a lo preceptuado en la Constitución de 1886, tal como ya se vio antes.

\section{La Ley 27/92 y la inscripción extraordinaria}

Esta ley contiene en su articulado una gran contradicción. Por un lado desarrolla el artículo 125 de la Constitución sobre el mérito y la vinculación a empleos de carrera administrativa, y por otro recogió la inscripción extraordinaria establecida en la Ley 61/87 y la hizo extensiva al nivel territorial donde por primera vez se aplicó la carrera administrativa. Lo anterior en abierta contradicción con el texto Constitucional que ya había establecido el concurso como único mecanismo para acceder

15 Ver Carta Política de 1886 sobre el tema de la función pública artículos 62-65 
a los empleos de carrera administrativa y el Congreso en vez de acatar este mandato prefirió reeditar lo establecido antes de la Constitución de 1991 a propósito del ingreso extraordinario.

En este contexto la Ley 27/92 en el artículo 22 estableció que

Al entrar en vigencia esta Ley, los empleados del nivel territorial que por virtud de ella llegaren a desempeñar cargos de carrera administrativa de conformidad con las normas vigentes, deberán acreditar dentro del año siguiente, el cumplimiento de los requisitos señalados en los manuales para los respectivos cargos o en las equivalencias establecidas en el Decreto 583 de 1984, Ley 61 de 1987 y Decreto Reglamentario 573 de 1988. Quienes no acrediten los requisitos dentro del término señalado, quedarán de libre nombramiento y remoción. No obstante, si tales empleados continúan al servicio de la Entidad u organismo, podrán solicitar su inscripción cuando lleguen a poseer los requisitos del cargo y los acrediten en debida forma.

Al comparar los dos textos en cuestión, es decir, los artículos 5 y 6 de la Ley 61/87 y el artículo 22 de la Ley 27/92 se ve la insistencia y el interés del Legislativo y del Ejecutivo de responderle a su cauda política en el sentido de asegurarle un puesto en la burocracia a como de lugar. Ambos textos incurren en exageraciones como las de autorizar a los empleados vinculados de manera provisional a inscribirse en el escalafón de la carrera teniendo como requisito el solo hecho de estar ahí en el momento preciso de la expedición de una y otra ley. Adicionalmente, si no cumplen los requisitos que se exigen para el desempeño del cargo respectivo, se les da un plazo para que los cumplan y una vez lo logren se inscriban. Es como permitirle a cualquier profesional para cuyo ejercicio se requiere el título, que ejerza y después cuando estudie presente el título que debió exigírsele para el ejercicio de la profesión, arte u oficio. Por último, una y otra ley se utilizaron para legalizar hechos cumplidos en el sentido de resolver el problema a los nominadores de haber posesionado a personas para desempeñar empleos públicos sin cumplir los requisitos.

En el caso de la Ley 27/92 se reglamentó a través del Decreto 1224/93. Allí se establece el procedimiento para la inscripción extraordinaria, se asignan tiempos y se establecen las responsabilidades de los funcionarios del área de recursos humanos de las entidades territoriales. Lo mismo 
acontece para los propios interesados en su inscripción extraordinaria, precisa los recursos que deben surtirse en cada etapa del proceso de la inscripción y otorga ciertas gabelas para los empleados interinos, en franca violación de la Constitución, tal como se analizará más adelante en este mismo acápite ${ }^{16}$.

¿Pero qué establece y ordena el artículo 125 de la Constitución de 1991?

Se dispuso que los empleos en los órganos y entidades del Estado son de carrera administrativa. Hay algunas excepciones referidas a los empleos de elección popular; los de libre nombramiento y remoción; los trabajadores del Estado y de sus entidades descentralizadas territorialmente y por servicios, y los que determine la ley. De otro lado, ordena que para ingresar a los cargos de carrera administrativa y el ascenso en los mismos, se hará previo cumplimiento de condiciones y requisitos que fije la ley para determinar los méritos y calidades de los aspirantes.

Es claro entonces que la propia Constitución establece el concurso como única vía para acceder a los empleos de carrera administrativa, para permanecer y ascender en ellos previa verificación de los méritos de los candidatos que participen en los concursos.

\section{Análisis sobre la fricción entre las ramas del poder público}

En las discusiones del Congreso sobre el texto de la Ley 27/92, se argumentó a favor de la inscripción extraordinaria el hecho de que ya se había realizado, al menos en dos ocasiones, la misma operación para los empleados del nivel nacional; adicionalmente, se esgrimió la experiencia específica de los empleados que en su condición de interinos aspiran a obtener derechos de carrera administrativa por mandato de la ley a sabiendas de que tal decisión legal es contraria a los principios de la Constitución. Se argumenta igualmente a favor de la inscripción extraordinaria, la generación de un problema en el sentido de que muchos

16 Para tener el panorama completo sobre el tema se recomienda ver el Decreto 1224/93 por el cual se reglamentaron los artículos 18 y 20 de la Ley 27/92 sobre la aplicación por primera vez de la carrera administrativa en las entidades territoriales. 
de los empleados en ejercicio hacen sus tareas de manera eficiente y al momento de ser reemplazados por un personal nuevo, ganador de los concursos, la eficiencia y la eficacia de la Administración Pública se verán deterioradas. Es contradictorio pero es un argumento poderoso. Tanto el Legislativo como el Ejecutivo estuvieron del lado de la inscripción extraordinaria y la ley en cuestión fue aprobada y surtió sus efectos durante algunos años hasta que fue demandada ante la Corte Constitucional; hecha la revisión de constitucionalidad se declaró inexequible por considerar que violentaba principios fundamentales como es el mérito de los aspirantes, verificado a través de los concursos para determinar la idoneidad de los candidatos.

La inscripción extraordinaria es espuria, no puede existir norma alguna dentro de nuestro ordenamiento que permita el ingreso automático a cargos de carrera

Esto lo determinó la Corte Constitucional a través de la Sentencia C-030 del 30 de enero de 1997, y con esta decisión parecía haber quedado resuelto el tema de lo obligatoriedad del concurso para acceder a los empleos de carrera, pero como veremos más adelante, el Legislativo y el Ejecutivo continuaron en su estrategia de favorecer a su clientela electoral exonerándola del concurso.

Los argumentos esgrimidos por la Corte Constitucional, en la sentencia citada, fueron los siguientes: a) la carrera administrativa es el instrumento idóneo para administrar a las personas vinculadas a la Administración Pública; b) el pilar de la carrera es el mérito y la capacidad de quien ha sido seleccionado para ingresar a ella; c) el concurso de méritos es, entonces, el mecanismo para evaluar todos los requisitos y calidades que deben reunir los aspirantes; d) las normas que posibilitan y ordenan la inscripción automática en la carrera administrativa tanto en los niveles nacional y territorial, van en contra de lo establecido en el artículo 125 que exige el mérito para ingresar a la carrera administrativa, y van en contra del artículo 13 Superior que predica el principio de igualdad y del 209 que establece la eficacia como principio que rige la función administrativa. Las excepciones que establecen las normas para acceder a la carrera desnaturalizan el sistema y anteponen el concepto de discrecionalidad de los nominadores impidiendo a los demás colombianos 
que, queriendo y teniendo las capacidades para desempeñarse como servidores públicos, lo puedan hacer.

Por las anteriores razones se declararon inexequibles los artículos de las leyes antes señaladas ${ }^{17}$. Pero, tales normas (art 5 y 6 de la Ley 61/87 y art 22 de la Ley 27/92) fueron declaradas contrarias a la Constitución años después de su entrada en vigencia, entonces, ¿qué hacer con las personas que lograron inscribirse de manera extraordinaria? Dado que la inexequibilidad surte efectos hacia el futuro, quienes lograron inscribirse en la carrera administrativa teniendo como fundamento normas que después se declaran inexequibles, generaron los derechos de permanecer en ella sin que hubiera razones para desconocer derechos adquiridos en presencia de normas legales vigentes al momento de adquirilos.

No obstante lo anterior, como vamos a ver más adelante, la misma Corte Constitucional ha decidido que algunas de sus sentencias tengan efectos retroactivos en cuyo caso no cabe la posibilidad de alegar derechos legítimos adquiridos en vigencia de disposiciones que luego fueron declaradas inexequibles.

\section{Una sola comisión nacional del servicio civil y miembros seleccionados por concurso público}

El texto inicial de la Carta de 1991 en su artículo 130 establece que habrá una Comisión Nacional del Servicio Civil responsable de vigilar y administrar las carreras de los servidores públicos excepto las que tengan carácter especial.

La intención de la Asamblea Nacional Constituyente fue crear un organismo de carácter técnico garante para que los mejores miembros de la sociedad que quieran contribuir con ella ofreciéndole sus talentos en el ejercicio de las tareas públicas, lo pueda hacer, pero participando previamente en franca lid en un proceso serio y transparente en que se verifiquen las calidades técnicas y los antecedentes éticos de los participantes.

17 Para una mayor profundización sobre el tema de la eliminación de la inscripción extraordinaria en nuestro sistema de carrera administrativa, se recomienda consultar las siguientes sentencias de la Corte Constitucional: C-030/97 Magistrado ponente Mario Arango Mejía; C-317/95 Magistrado ponente Eduardo Cifuentes Muñoz; C-037/96 Magistrado ponente Vladimiro Naranjo Mesa; C-562/96 /96 Magistrado ponente Alejandro Martínez Caballero. 
La idea era, entonces, crear y organizar una comisión de la más alta jerarquía en materia de carrera administrativa, pero al desarrollar el mandato anterior, el Congreso incurrió en dos ocasiones (Ley 27/92 y Ley 443/98) en abierta contradicción con la Constitución Política, disponiendo no solamente la organización y funcionamiento de una Comisión Nacional del Servicio Civil sino, extralimitándose en sus atribuciones, creando y organizando tantas comisiones de servicio civil como departamentos existen, más la del Distrito Capital.

Fue necesario entonces, esperar varios años a que se presentaran las acciones públicas en defensa de la Constitución y contra las leyes antes mencionadas, para que la Corte se ocupara del asunto y decidiera definitivamente sobre la conformidad o no de las mismas frente al texto de la Carta.

\section{Sentencia 372/99 y parálisis de la carrera administrativa}

Al declararse la inexequibilidad de la Ley 443/98, la Corte Constitucional precisó lo siguiente: a) Al tenor del artículo 130 de la Constitución de 1991, la Comisión del Servicio Civil es, una sola y, a juicio de la Corte, no tiene un carácter de cuerpo asesor o consultivo de los Gobiernos nacional o territorial; b) No es una junta o consejo directivo de composición paritaria o con mayoría prevalente de los organismos estatales o de los trabajadores; c) Tampoco es consejo consultivo de las entidades territoriales en cabeza de sus autoridades tal como se refleja en los textos que se examinan; d) Se trata en realidad de un ente autónomo, de carácter permanente y de nivel nacional, de la más alta jerarquía en lo referente al manejo y control del sistema de carrera de los servidores públicos, cuya integración, período, organización y funcionamiento deben ser determinados por la ley; e) No hace parte del Ejecutivo ni de otras ramas u órganos del poder público y debe ser dotada de personería jurídica, autonomía administrativa y patrimonio propio, para que pueda cumplir con eficiencia los cometidos constitucionales que le corresponden; f) Considera la Corte, por una parte, que si la Comisión Nacional del Servicio Civil establecida por la Constitución es un organismo único, ningún sentido tiene la existencia de comisiones independientes a nivel territorial, cuya función descoordinada e inconexa desvertebraría por 
completo la estructura que la Constitución ha querido configurar en los términos descritos, frustrando los propósitos esenciales de sus artículos 125 y $130^{18}$. Con esta sentencia se sacó del ordenamiento jurídico lo fundamental para que la institución de la carrera administrativa pudiera aplicarse. Ante tal situación, la Corte Constitucional en sus consideraciones, exhorta al Congreso para que a la mayor prontitud y con arreglo a los términos de esta Sentencia C-372/99 expida la ley que ordena el artículo 130 de la Carta y se llene el vacío que se presentaba al entrar a regir la sentencia mencionada.

\section{Cinco años y medio sin carrera administrativa}

Al declararse contrarias a la Constitución las partes fundamentales de la Ley 443/98, se inicia un periodo de parálisis de la carrera administrativa que va desde el 26 de mayo de 1999 hasta el 16 de diciembre de 2004 cuando se instala la Comisión Nacional del Servicio Civil de conformidad con la Ley 909/04. Ese fue el tiempo que tardaron tanto el Ejecutivo como el Legislativo para llenar el vacío que se presentó al declararse inexequible la ley 443/98 no obstante la exhortación que les hizo la Corte Constitucional para que en un breve plazo se expidiera la ley pertinente.

Transcurrieron, entonces, más de cinco años y medio sin el sistema de carrera para ingresar, evaluar y promover a los empleados del servicio civil. En el ínterin se produjeron muchas vacantes definitivas en cargos de carrera administrativa debido al crecimiento de las agencias del Estado, al reacomodamiento de algunas de ellas, al retiro por distintas causas de empleados que ocupaban cargos de carrera administrativa. Esta situación dio lugar a que los responsables de dirigir las entidades del Estado, en sus distintos niveles, nombraran de manera provisional, supuestamente, a quienes llenaban los requisitos para ocupar los cargos de carrera vacantes. Es un periodo de gran comodidad para los nominadores porque pudieron responder con creces a las presiones de los grupos, movimientos y partidos políticos que reclamaban puestos en la burocracia. Es decir, se

18 Se recomienda ver texto completo en C-372/99 con ponencia del Magistrado José Gregorio Hernández. 
recuperaron las costumbres del patronazgo, del cacicazgo y del clientelismo; en resumen, el spoil system.

Los empleados así nombrados - de manera provisional-y posesionados, con el paso de los meses y de los años más allá del límite permitido, que para esa época era de cuatro meses (ver Ley 443 art 10), consideraban que tendrían derechos adquiridos, y que cuando llegara el momento preciso deberían ser inscritos en el escalafón de carrera administrativa o al menos ser sujetos de un tratamiento preferencial. Tales argumentos fueron muchas veces esgrimidos ante la Corte Constitucional vía tutelas, y en todas las ocasiones fueron desestimados por las instancias competentes, tal como se verá más adelante.

\section{Ley 909/2004 y los rezagos del clientelismo}

Con esta ley se activó nuevamente el sistema de carrera administrativa en el país, y al mismo tiempo en el artículo 56 se estableció que los tratamientos especiales, léase clientelares, para quienes desempeñaban de manera provisional ${ }^{19}$ cargos de carrera. En cuanto al número de provisionales, tal como se dijo antes se contaban por decenas de miles; al respecto la apoderada del Departamento Administrativo de la Función Pública -DAFP-en su participación en defensa del artículo en comento ante la Corte Constitucional afirmó:

se desconoce el número total de provisionales que trabajan en la administración pública, pero solo en el orden nacional se aproximan a treinta mil los empleados de ese carácter, mientras que en las entidades territoriales su número es más incierto, pero no sería descabellado hablar de unos noventa mil.

Esta situación se debió al tiempo excesivamente largo que tomaron el Ejecutivo y el Legislativo para llenar el vacío ante la declaratoria de

19 El artículo 56 de la ley otorgó ventajas a quienes desempeñaban cargos de carrera y participaran en el concurso para seleccionar a quienes deberían ocuparlos "definitivamente", al disponer que en el análisis de antecedentes se les evaluará y reconocerá la experiencia, antigüedad, conocimiento y eficiencia en su ejercicio. La Comisión Nacional del Servicio Civil adoptará los instrumentos para tal efecto. Para profundizar en el tema se sugiere ir al texto inicial de la Ley 909/2004. 
inexequibilidad de la Ley 443/98. Sobre este tema la apoderada del DAFP, en la defensa aludida de la norma, ente la Corte Constitucional también afirmó:

A partir de 1999 se suspendieron los procesos de selección de ingreso al empleo público de carrera, paralizando así el sistema, razón por la cual la administración pública ha visto florecer un número desproporcionado de provisionales y de empleos provistos por encargos que han convertido el sistema de carrera en un "mero adorno". (Sentencia C-733/2005)

Estos miles de empleados públicos interinos tenían padrinos políticos con los cuales se configuraron pactos de fidelidad, debido a que en dicho periodo se produjeron varios comicios electorales. Entre más tiempo pasara sin resolver el problema y mayor fuera el número de provisionales, más presión para las instancias del Estado encargadas de velar por el cumplimiento de los principios de la igualdad y del mérito. Los elegidos de un lado, -congresistas y presidente de la República-, y los provisionales del otro lado, hicieron causa común; los primeros, por la forma de ganar votos en las contiendas electorales, se apropiaron de las banderas de los provisionales y pretendieron, vía leyes ad hoc, solucionarles el problema de la interinidad. En esta ocasión tampoco coincidieron los criterios del Ejecutivo y del Legislativo frente a los de la Corte Constitucional a propósito del sistema de mérito que debe presidir el proceso de selección de quienes habrán de vincularse a la carrera administrativa. Esta fricción entre las ramas del poder público se muestra a continuación.

Sentencia C-733/200520

Encuentra la Corte Constitucional que el artículo 56 de la ley 909/04 consagra y otorga trato desigual y privilegiado a quienes el 23 de septiembre de 2004, fecha de publicación de la ley mencionada, se encontraban en

20 Esta sentencia declara la inexequibilidad del artículo 56 de la Ley 909/2004 por varias razones que violentan el espíritu de la Constitución en esta materia, en especial los principios de la igualdad y el derecho de participar en la conformación, ejercicio y control del poder político. Ver Sentencia C-733/2005 Magistrada ponente Clara Inés Vargas Hernández. 
situación de interinidad desempeñando cargos de carrera administrativa y participen en concursos abiertos para seleccionar a quienes habrán de desempeñar dichos cargos en propiedad.

Las razones, entre otras, que esgrimió la Corte Constitucional para sustentar la Sentencia de Marras son las siguientes: a) el concurso está encaminado a establecer los méritos de los candidatos; b) los provisionales por el hecho de participar en los concursos no adquieren por ese solo hecho el derecho de que se les confirme en sus cargos; c) el Legislador sí es competente para determinar condiciones y requisitos para la selección del personal que ingresa a la Administración Pública pero no le es permitido establecer procedimientos que desconozcan el principio de igualdad a todos los participantes ${ }^{21}$.

Como se aprecia esta vez tampoco tuvieron sindéresis el Ejecutivo y el Legislativo al desarrollar la Constitución en lo atinente a fortalecer el sistema de mérito para ingresar a la función pública y acabar con el amiguismo y el clientelismo.

\section{El Legislativo y el Ejecutivo no se dan por vencidos: Ley 1033/06}

Dos años después de la expedición de la Ley 909/04 y de haber sido declarado inexequible el tema de la validación masiva de manera especial del desempeño de los provisionales que participaran en los concursos de méritos, el Gobierno nacional y los congresistas deseosos de solucionar el ingreso casi "directo" a la carrera administrativa, esta vez en el sector defensa, expiden la Ley 1033/06. Allí se ordena que quienes estén vinculados de manera provisional en cargos de carrera administrativa, con una antelación de seis meses a la fecha de expedición de esta ley, en el proceso de selección, se les exonerará de las pruebas básicas de conocimientos bajo el supuesto que tal antigüedad la podría suplir ${ }^{22}$.

21 Para ver la tendencia de la Corte Constitucional sobre el tema de la carrera administrativa y los principios que la rigen se aconseja ver sentencias como las siguientes: C- 074/04 Magistrada ponente Clara Inés Vargas Hernández; C-371/00 Magistrado ponente Carlos Gaviria Díaz; C-808/01 Magistrado ponente Manuel José Cepeda; C-714/02 Magistrado ponente Alfredo Beltrán Sierra.

22 En el artículo 10 la Ley 1033/06 ordenó la homologación de la prueba básica o de conocimientos generales por la experiencia mínimo de seis meses en el respectivo cargo que se 
Esta vía del atajo para resolver dicho problema ha sido objetada varias veces por la Corte Constitucional; no obstante, las otras dos ramas insisten de manera absurda haciendo caso omiso de las reiteradas sentencias de la Corte. Como era de suponerse en la primera acción pública de revisión de constitucionalidad se declara inexequible el artículo 10 de la Ley 1033/06.

Sentencia C-211/0723 y la inexequibilidad del artículo 10 de la Ley 1033/06

En esta sentencia se hace una recopilación de posturas adoptadas por la Corte Constitucional a propósito de la revisión de varias disposiciones legales sobre el tema de la carrera administrativa y todas sirven para formar una tendencia en el sentido de hacer prevalecer los postulados de la Constitución independiente de razones coyunturales de conveniencia aducidas por las otras ramas del Poder público al momento de discutir, aprobar y sancionar las leyes.

La Corte Constitucional al sacar del ordenamiento jurídico la disposición antes señalada adujo, entre otras, las siguientes razones: a) respeto del principio de mérito; b) la experiencia obtenida en el cargo objeto del concurso no pude ser factor de discriminación; c) es claro que al ordenarse la realización de una prueba en la que se da un mayor valor a la experiencia relacionada con el cargo objeto de concurso, se favorece necesariamente a quienes los estén desempeñando, lo cual va en detrimento de los demás concursantes; d) esta situación de desigualdad va en contra de los artículos 13, 40-7 y 125, de la Carta; e) por las razones anteriores lo que procede es declarar la inexequibilidad de los incisos 1 , 2, y 3 del artículo 10 de la Ley 1033/06.

Nuevamente los principios contenidos en la Constitución se mantienen incólumes ante los embates bajo cierta correlación de fuerzas entre el Ejecutivo y el Legislativo, por un lado, y la Corte Constitucional como guardiana de la Carta, por el otro.

está desempeñando y para el cual se concursa. Además, se imparten precias instrucciones a la Comisión Nacional del Servicio Civil para que proceda otorgándole términos perentorios.

23 Ver Sentencia C-211/07 Magistrado ponente Álvaro Tafur Galvis. 


\section{Novedad en la jurisprudencia de la Corte Constitucional}

Por regla general las sentencias de la Corte Constitucional tienen efecto hacia el futuro, es decir, a partir de la fecha de las sentencias, presentándose así la consolidación de derechos amparados por disposiciones que estuvieron vigentes antes de la declaratoria de su inexequibilidad. No obstante, en este caso se presenta un viraje de ciento ochenta grados, dado que los efectos de la Sentencia 211/07 no fueron a partir del 21 de marzo de 2007 fecha de su expedición, sino a partir del 18 de julio de 2006, fecha de expedición de la Ley 1033/06, con lo cual deja sin efectos los actos administrativos impulsados en vigencia de los incisos 1, 2, y 3 del artículo 10 de la Ley 1033/06; los cuales, a la postre, se sacaron del ordenamiento jurídico, con el agravante para la Administración de que sus actuaciones quedaron sin piso o sustento jurídico y lo actuado no tendrá validez, lo que hace que sea necesario iniciar los procesos de selección desde la vigencia de la Ley 1033/06, sin la presencia de los incisos declarados inexequibles. En este caso, igualmente se impone el criterio de la Corte Constitucional en defensa de la Carta de 1991 en materia de carrera administrativa.

Es claro que la Ley 1033/06 contempla un claro desconocimiento del principio de mérito para ingresar al colectivo de la carrera administrativa en particular y a la Administración Pública en general. Para resolver este exabrupto que posibilita disfrutar y consolidar situaciones de confort a un grupo de colombianos sin que haya mérito para ello, es necesario, entonces, dijo la Corte Constitucional:

dar efectos retroactivos a la Sentencia [...] y estarse a la clara línea jurisprudencial de esta Corporación. [Así las cosas, agregó la Corte], se atenderá la solicitud de la demandante en el proceso D-6469 de dar efectos retroactivos a la sentencia en este punto y en ese sentido en armonía con reiterada jurisprudencia, a la decisión de inexequibilidad que se profiere respecto de los incisos primero y segundo del artículo 10 de la Ley 1033 de 2006 se le darán efectos desde la fecha de publicación de la ley referida. 


\section{La constitución se cumple, se respeta y no se sustituye}

Con la casuística antes analizada, podría inferirse que las ramas del poder público trabajarían separadamente pero en armonía, tal como lo dispone la Constitución de $1991^{24}$ pero la realidad muestra comportamientos aún más disímiles y de permanente fricción.

Acto Legislativo 01/08: Se sustituye parcial y temporalmente la Constitución con la adición de un parágrafo al artículo 125

Como por vía de leyes ordinarias el Ejecutivo y el Legislativo no tuvieron éxito para resolver la interinidad de más de 120000 empleados públicos en los niveles nacional y territorial, se dieron a la tarea de modificar la Constitución con ese solo propósito y para tal efecto se expidió el 26 diciembre de 2008 el Acto Legislativo 01/08 por medio del cual se adiciona un parágrafo transitorio al artículo 125 de la Constitución ${ }^{25}$. Este artículo es la médula vertebral de la carrera administrativa en Colombia y ha sido el gran obstáculo para políticos y nominadores habituados a disponer de las plantillas de cargos a su entero arbitrio. Romper esta barrera constitucional, por parte de la clase política, ha sido por largos años un propósito, a veces velado, a veces con discusiones abiertas, cuyo fin es el de volver a la situación del spoil system o teoría del despojo. Es decir, quien gana el poder en las contiendas electorales gana también el poder para disponer de las nóminas, del presupuesto y de la contratación administrativa. Todo lo cual responde a prácticas muy arraigadas de hacer política en Colombia.

Los elementos fundamentales del acto legislativo en comento, se pueden resumir así: a) se establece un plazo de tres años contados a partir de

${ }^{24}$ El artículo 113 de la Constitución dispone que los órganos del Estado poseen funciones separadas pero trabajan armónicamente para la realización de sus fines.

25 El acto legislativo establece, en su conjunto, los elementos que la Corte Constitucional ya había declarado inexequibles y en tal sentido bien podría entablarse un juicio de responsabilidades a los servidores públicos que insisten en elevar a norma legal o constitucional temas que ya fueron analizados por la Corte Constitucional y sacados del ordenamiento jurídico. El artículo 243 de la Carta establece que las decisiones de la Corte Constitucional en virtud del ejercicio de control jurisdiccional hacen tránsito a cosa juzgada constitucional. Ninguna autoridad podrá reproducir el contenido material del acto jurídico declarado inexequible por razones de fondo mientras exista el mismo texto constitucional que sirvió para hacer la confrontación. 
la expedición del acto legislativo para que la Comisión del Servicio Civil, inscriba de manera extraordinaria y sin concurso a todos los empleados que ocupaban y sigan ocupando, de manera provisional, cargos de carrera administrativa al momento de la expedición de la Ley 909/04 (o sea el 16 de septiembre de 2004); b) se suspenden todos los concursos que se estén adelantando por mandato de las leyes 909 y 1033, incluidas las carreras especiales y los sistemas específicos de administración de personal, con excepción de los pertenecientes a la carrera judicial y a la notarial; c) la Comisión Nacional del Servicio Civil diseñará, dentro de los tres meses siguientes, instrumentos de evaluación del desempeño para los empleados inscritos de manera extraordinaria en carrera administrativa.

Se puede apreciar, entonces, que lo que no pudieron hacer el Ejecutivo y el Legislativo a través de leyes ordinarias, ahora se pretendía lograrlo modificando "sobre medidas" la Constitución. El acto legislativo incurrió en violaciones tan flagrantes a varios principios consagrados en la Constitución que a título de ejemplo se pueden mencionar los siguientes: la igualdad; el derecho al trabajo; el derecho a participar en la conformación; ejercicio y control del Poder político, y el mérito como condición para ingresar a la carrera administrativa, la transparencia y la eficacia de los procedimientos administrativos. De otro lado, ha quedado claro que tanto el Legislativo como el Ejecutivo conocían no solo el espíritu de la Constitución en materia de función pública, sino la postura adoptada y reiterada de la Corte Constitucional sobre el tema.

\section{Sentencia 588/09 y sus efectos retroactivos ${ }^{26}$}

Fue una decisión cuya preparación involucró conceptos de las partes directamente concernidas como la Comisión Nacional del Servicio Civil, el Departamento Administrativo de la Función Pública (DAFP), algunos sindicatos, ciudadanos coadyuvantes en pro y en contra de la norma demandada, Facultades de Derecho y la vista Fiscal. El DAFP, los sindicatos

26 Esta sentencia constituye un hito en la jurisprudencia de la Corte Constitucional por varias razones: la declaratoria de inexequibilidad de un acto legislativo; la retroactividad de sus efectos; la clara postura y responsabilidad asumida por la Corte Constitucional en defensa de la Constitución, su espíritu y sus principios. Se recomienda ver el texto de la Sentencia C-588/09 Magistrado ponente Juan Carlos Henao Pérez. 
y algunos ciudadanos solicitaron a la Corte Constitucional declarar exequible el Acto Legislativo 01/08, mientras que la Comisión Nacional del Servicio Civil, la Facultad de Jurisprudencia de la Universidad del Rosario, algunos ciudadanos y la vista Fiscal solicitaron que se declara contraria a la Constitución y se sacara del ordenamiento jurídico la norma en cuestión.

Del análisis hecho por la Corte Constitucional, tanto material como formal, del acto legislativo, se concluye que: a) el Congreso ha incurrido en una sustitución parcial y temporal de los principios de la carrera administrativa contenidos en el artículo 125 de la Constitución por otro totalmente distinto; b) el parágrafo que se pretende adicionar al artículo 125 no solo es contrario a los demás incisos del mismo artículo, sino que modifica tácitamente y de manera temporal varios artículos de la Carta. La Corte Constitucional en varias sentencias ha precisado que si bien la Constitución le confiere la competencia para conocer y decidir sobre las revisiones de constitucionalidad que presenten los ciudadanos sobre los actos legislativos solo por vicios de forma (mayorías, consecutividad, términos para el trámite de discusión, aprobación y sanción, entre otros elementos formales) no es menos cierto que, ante una reforma constitucional, le confiere competencia para examinar si el constituyente derivado, al ejercer el poder de reforma, incurrió o no en un vicio de competencia; c) el poder del Congreso tiene límites competenciales los cuales los ha fijado la propia Carta en el sentido de que el Congreso sí puede revisar para reformar la Constitución vigente, pero no para sustituirla por otra Constitución, lo cual en el sentir de la Corte es atribución del constituyente originario; d) la sustitución consiste en reemplazar un texto por otro, so pretexto de reformar el texto inicial; se trata de la introducción de un nuevo texto completamente distinto, que a la postre resulta una Constitución con elementos nuevos que reemplazan los originalmente adoptados; e) el examen entre los dos textos, el antiguo y el nuevo se hace para determinar si los principios o elementos introducidos armonizan o no de manera integral con el resto de los elementos que no se modifican y que están dispersos a lo largo del texto completo de la Constitución, o por el contrario son opuestos o diferentes a tal punto que resulten incompatibles, especialmente frente a ciertos principios o elementos que se consideran insustituibles; $\mathrm{f}$ ) en el caso concreto del parágrafo que adiciona el Acto Legislativo 01/08 al artículo 125 de la Constitución, es clara la 
suspensión de la regulación de la carrera administrativa allí contemplada y del resto de disposiciones de la Carta referidas tanto a las carreras administrativas especiales como a los sistemas específicos de administración de personal, cuyo propósito es el de valorar el mérito como condición sine qua non para ingresar al servicio civil de carrera; g) con la sustitución temporal introducida al principio del mérito y la consiguiente inscripción extraordinaria en la carrera administrativa se entronizan ventajas desmedidas y gratuitas en favor de quienes el único mérito que muestran es el de haber llegado primero a los cargos que desempeñan en calidad de provisionales, dejando por fuera de la competencia a todos los aspirantes cobijados por el mandato Superior contenido en el artículo 40.7 cuya vigencia, al igual que la de muchos otros, queda tácita y temporalmente suspendida, y h) la Corte ha precisado que con el fin de proscribir las arbitrariedades que favorezcen a algunos y perjudican a otros, las reglas de juego deben tener unos mínimos de universalidad que regulen de igual manera a situaciones iguales y no prohijar reglas ad hoc; es decir, aquellas que sirven exclusivamente para ser aplicadas a casos y sujetos predeterminados, situaciones en las cuales las reformas están revestidas con un tinte puramente político.

\section{Efectos retroactivos de la sentencia}

De acuerdo con el análisis y razones antes expuestas, la Corte Constitucional declara a través de la Sentencia C-588/09, inexequible el Acto Legislativo 01/08, precisando que la sentencia surtirá sus efectos retroactivos a partir de la fecha de la expedición del acto legislativo que se declara inexequible, quedando igualmente sin efecto los actos que se hayan expedido durante el tiempo transcurrido entre su expedición y la declaratoria de su inexequibilidad.

La Corte Constitucional declara que está facultada para determinar la fecha a partir de la cual surten efectos sus sentencias. Por eso en esta ocasión, dado que el acto legislativo pretendía introducir una solución de continuidad en la vigencia de mandatos constitucionales cuya esencia es su carácter permanente, se hace necesario, entonces, sustraer de la vida jurídica el acto legislativo de marras, el mismo día en que se pretendía que entrara a regir. Consecuentemente con lo anterior, ordena la 
Corte que los concursos de méritos suspendidos por mandato del acto legislativo declarado inexequible deben reanudarse retomando el estado de los trámites al momento en que se suspendieron; debe permitirse la inscripción a nuevo aspirantes y determinar la carencia de valor y efecto a todas las inscripciones extraordinarias en la carrera administrativa por ser contrarias a la Constitución.

Acto Legislativo 04/2011 por el cual se incorpora un artículo transitorio a la Constitución Política de Colombia

La esencia de este episodio contenida también en un acto legislativo, tenía como propósitos los siguientes: a) para quienes estén a 31 de diciembre de 2010 desempeñando en calidad de provisionales, empleos de carrara administrativa, se autoriza a la Comisión Nacional del Servicio Civil para que en los procesos concursales para ingresar a la carrera administrativa se les homologen las pruebas de conocimiento establecidas en el concurso público, preservando el principio del mérito, por la experiencia y los estudios adicionales a los requeridos para ejercer el cargo. Para tal efecto se establece una tabla en la cual se establecen los puntos que se otorgarán en cada caso y para cada nivel administrativo (asesor, profesional, técnico y asistencia); b) para los inscritos en carrera administrativa y que a la fecha (léase 7 de julio de 2011 fecha en que se expide el acto legislativo) lleven tres años encargados de otros cargos de carrera administrativa, y hayan obtenido calificación de servicios sobresaliente en el último año al momento de realizar los concursos respectivos se les evaluará con la misma tabla referida en el literal anterior; c) a los integrantes de la carrera judicial y docente no les aplicará el Acto Legislativo 04/201127.

Es evidente, entonces, la "lucha" dada por el Ejecutivo y el Legislativo y su interés por responder a su clientela política en el sentido de asegurarles un puesto en la burocracia con el menor esfuerzo posible de parte de los beneficiarios y en detrimento de los intereses de la sociedad

27 Se recomienda ver los detalles de la tabla que establece los estudios, experiencia específica y los puntos correspondientes para las homologaciones ordenadas en el Acto Legislativo $04 / 2011$. 
que tiene derecho a seleccionar a sus mejores miembros para ponerlos a su servicio.

\section{Sentencia 249/2011}

A través de esta sentencia se resolvieron las demandas de revisión de constitucionalidad contra el Acto Legislativo 04/2011 y como es sabido, la Corte notifica a las partes concernidas y comunica a los ciudadanos para que ejerzan el derecho de coadyuvar a los demandantes o para que expongan sus argumentos en defensa de la norma que se demanda. A continuación se relacionan las ideas fuerza de quienes manifestaron su acuerdo o desacuerdo con el texto demandado.

El Presidente de la Comisión Nacional del Servicio Civil, órgano encargado de vigilar y controlar las carreras administrativas, consideró que el Acto Legislativo 04 de 2011 evidencia un exceso de la competencia del Congreso en el ejercicio de sus funciones para modificar la Constitución dado que las normas demandadas comportan una sustitución parcial y temporal de la Constitución; con tales normas se establecen privilegios arbitrarios y por consiguiente se violenta el principio a la igualdad que tienen todos los ciudadanos para acceder a la función pública. Por lo tanto, solicita a la Corte declarar la inexequibilidad de dicho acto legislativo.

El Departamento de Derecho Administrativo de la Universidad Externado de Colombia considera que se presentó un vicio competencial, que induce a la inconstitucionalidad de la norma demandada. Las razones que aduce para su juicio se refieren al hecho de que el sistema de carrera administrativa se articula con el aseguramiento de los fines del Estado y de la función administrativa, con varios derechos fundamentales como el de la igualdad y el acceso al servicio público, entre otros. Agrega además, que al homologar la experiencia por el conocimiento a los provisionales, se hace un juicio a priori en el sentido de que la permanencia en los cargos les da la solvencia de conocimientos y los hace los mejores y los acreedores de la máxima calificación entre todos los aspirantes.

El Procurador General de la Nación solicita a la Corte que se declare la inexequibilidad del Acto Legislativo 04 de 2011, entre otras razones, porque 
se incurre en los mismos defectos de las disposiciones expulsadas del ordenamiento en la sentencia C-588 de 2009 ya que al eliminar la prueba de conocimiento, priva al concurso público de méritos, del principal elemento objetivo para determinar el mérito de los aspirantes.

Varios ciudadanos hicieron llegar a la Corte sus argumentos y la solicitud de que se decrete la inconstitucionalidad del Acto Legislativo 04 de 2011 porque eso es violatorio de los principios del mérito y de la igualdad; porque sustituye parcial y temporalmente varios artículos de la Carta en beneficio de unos pocos, y porque la Corte ya se había ocupado del asunto a través de la Sentencia C-588/09.

La Corte Constitucional (Sentencia C-249 de 2011), ante todo, hace un pormenorizado análisis tanto de sus competencias como de las del Congreso e identifica una serie de valores y principios que caracterizan a la Constitución de 1991; igualmente se refiere al control entre los poderes y al parámetro de control de constitucionalidad contenido en el Título XIII de la Carta, el cual contiene una limitación del Legislativo en el sentido de que "so pretexto de la reforma, el constituyente derivado o secundario no puede sustituir la Carta, porque, en tal caso, asume funciones propias del constituyente originario o primario" 28 .

Las ideas fuerza tenidas en cuenta por la Corte para determinar si la norma que se demanda es o no contraria a la Constitución son las siguientes: a) se verifica si las normas que se pretenden modificar siguen siendo las mismas antes y después de la pretendida reforma. Si se mantienen, es decir, si siguen siendo las mismas o idénticas, entonces no existió reforma, sino que se le ha dado apariencia de reforma a una decisión política "singular" o sea ad hoc para favorecer a unos sujetos predeterminados, en desmedro de los principios de generalidad o universalidad inherente a todo precepto constitucional; b) la carrera administrativa como sistema técnico de administración de personal al servicio del Estado está integrada a unos principios constitucionales que están consagrados de manera transversal en la Carta y se refieren a garantizar los derechos fundamentales de los asociados, al respeto del principio de igualdad y

28 Para una visión amplia sobre los test que aplica la Corte Constitucional para determinar si los actos legislativos son o no contrarios a la Carta se recomienda ver la Sentencia C-249 de 2012, Magistrado ponente Juan Carlos Henao Pérez. 
al cumplimiento de los fines del Estado; c) del cotejo del texto del acto legislativo frente a las normas supuestamente modificadas, se aprecia que el texto de la Constitución se mantiene incólume, lo cual permite concluir que de lo que se trata es de sustituir temporal y parcialmente el principio de la igualdad para posibilitar que a los empleados provisionales se les tenga en cuenta, además de las pruebas que contempla el concurso de méritos, criterios adicionales como la experiencia específica en los cargos para los cuales se concursa, más los cursos de formación y capacitación que hayan podido adelantar mientras se desempeñaron en tales cargos; d) el puntaje establecido en el acto demandado, a favor de los provisionales sustituye el principio estructural de la carrera administrativa que es la evaluación del mérito en condiciones de igualdad para todos los participantes; e) constató la Corte que con el Acto Legislativo 04 de 2011, el Congreso quebrantó un principio axial de la Constitución, sustituyéndolo por otro completamente diferente, con el fin de imponer una decisión en favor de sujetos predeterminados.

Por los anteriores motivos la Corte decide declarar inexequible el Acto Legislativo 04 de 2011. Esta decisión se tomó el 29 de marzo de 2012 pero se entiende que al igual que lo acontecido con el Acto Legislativo 01 de 2008, sacarlo del ordenamiento jurídico significa que uno y otro nacieron muertos y por consiguiente no produjeron efectos. Además, en el evento en el que se haya impulsado algún acto administrativo entre la fecha de su expedición y la fecha de su exclusión del ordenamiento jurídico, este no surtirá ningún efecto.

\section{A manera de conclusión}

Durante la vigencia de la Constitución de 1991, el tema de la función pública en general y de la carrera administrativa en particular, ha sido objeto de las mayores y más frecuentes controversias entre las ramas del poder público. De un lado, el Legislativo y el Ejecutivo y de otro lado, la Corte Constitucional como guardiana de la Constitución.

Las controversias o fricciones que se presentan han tenido dos niveles de confrontación: el primero con la expedición de leyes y el segundo con la expedición de actos legislativos. En ambos casos la constante ha 
sido el deseo claro del Congreso y del Gobierno por eludir los principios que presiden la carrera administrativa y sus instrumentos como son el concurso y la valoración de los antecedentes de los aspirantes para seleccionar a los mejores y vincularlos a la función pública desde donde habrán de servir a la sociedad, independientemente del color político de quienes estén en el Gobierno.

Es claro, por lo que han hecho, que el Gobierno y el Congreso quieren la carrera administrativa pero para sus clientelas políticas, con las cuales adquieren compromisos en sus campañas políticas y una vez se hacen con el poder, desde allí accionan por todos los medios para garantizarles un puesto en la burocracia.

Para conseguir lo anterior, en un primer plano, han tramitado varios proyectos, algunos se han convertido en leyes de la República, pero todos tienen un mismo sello que consiste en ir a contrapelo de la Constitución, la misma que juraron defender cuando se posesionaron como servidores públicos.

Las principales decisiones tomadas por el Legislativo y el Ejecutivo, consideradas espurias por la Corte Constitucional, pasan por los siguientes propósitos: a) permitir a los nominadores que de la lista de elegibles pudieran nombrar a uno de los tres o a uno de los cinco primeros, en detrimento del derecho del ganador del concurso; b) conceder beneficios de distinta índole y sin justificación alguna como el ingreso automático a la carrera a todos los empleados que ocupaban empleos de carrera de manera provisional, y c) valorar de manera especial los antecedentes y experiencia específica a los provisionales y a quienes estuvieran encargados de empleos superiores.

En todos estos casos, tal como se mostró, la Corte Constitucional en defensa del espíritu y valores contenidos en la Carta, declaró inexequibles las leyes que establecían privilegios sin razón, y dio al traste con las pretensiones de los autores de tales normas y de los intereses de los potenciales beneficiarios.

En un segundo plano, y ante los fracasos con sus leyes, el Congreso y el Gobierno no dan su brazo a torcer e insisten en dos ocasiones, a través de la modificatoria de la Constitución vía actos legislativos. En el primer acto legislativo $(01 / 08)$ se pretendía agregar un parágrafo al artículo 125 de la Constitución, que es la columna vertebral de la carrera 
administrativa para suspender su vigencia mientras se tramitaban sus pretensiones en favor de su clientela electoral enquistada en los cargos públicos en calidad de provisionales y decretar para ella, el ingreso masivo de los provisionales a la carrera administrativa y a la vez suspender los concursos que para la época adelantaba la Comisión Nacional del Servicio Civil. Ante las primeras demandas, la Corte Constitucional declara inexequible el acto legislativo antes mencionado $\mathrm{y}$, además, con efectos retroactivos, deja en ceros las pretensiones del Gobierno y del Congreso. Ante tal escenario, estos vuelven a contra atacar expidiendo un segundo acto legislativo (04/2011) por el cual se adiciona un artículo transitorio a la Carta de 1991 en el cual se ordena valorar a los provisionales de manera especial su experiencia específica en los cargos para los cuales concursan y los cursos de formación y capacitación que hubieran hecho con el fin de que se les homologuen por las pruebas en los procesos concursales; con lo cual concedían ventajas a su clientela, en detrimento de los demás aspirantes.

En estos casos, la Corte Constitucional también defendió la Constitución y le mostró a las otras ramas del poder público que el procedimiento utilizado para tomar sus decisiones vulnera competencias asignadas al Congreso para modificar la Constitución. Lo que se hizo a través de los actos legislativos mencionados, fue sustituir parcial y temporalmente la Constitución para resolver un problema a sujetos predeterminados, lo cual es abiertamente inconstitucional. Por lo tanto, tales actos legislativos fueron sacados del ordenamiento jurídico con las obvias consecuencias. Así se resolvieron los dos últimos embates del Legislativo y del Ejecutivo a propósito del tema de la carrera administrativa.

Se espera que ahora haya suficiente claridad sobre lo que estipula la Carta sobre el tema en cuestión y se proceda en consecuencia, de conformidad con lo establecido en el artículo 113 de la Constitución.

$\mathrm{Al}$ analizar estos compartimentos asumidos por las Ramas del Público, vale la pena preguntarse cuánto pudo ahorrarse la sociedad en el evento en que, siguiendo los mandatos constitucionales, se hubiera trabajado armónicamente, bajo el lema de legislar en aras del bien común. Pero como se mostró, hubo momentos en que a la hora de legislar pesaron más los intereses clientelares y las relaciones de cacicazgo, los cuales hicieron 
de la función pública una mercancía en que la regla de transacción es la incompatibilidad del interés partidista frente al interés general.

\section{Referencias}

Asamblea Nacional Constituyente. (7 de julio de 1991). Gaceta Constitucional (114), 1-36.

Colombia, Congreso de la República. Ley 165 de 1938 Por la cual se crea la carrera administrativa (29 de octubre de 1938).

Colombia, Congreso de la República. Ley 61 de 1987 Por la cual se expiden normas sobre la Carrera Administrativa y se dictan otras disposiciones (31 de diciembre de 1987).

Colombia, Congreso de la República. Ley 27de 1992 Por la cual se desarrolla el artículo 125 de la Constitución Política (29 de diciembre de 1992).

Colombia, Congreso de la República. Ley 270 de 1996 Estatutaria de la Administración de Justicia (15 de marzo de 1996).

Colombia, Congreso de la República. Ley 443 de 1998 por la cual se expiden normas sobre carrera administrativa y se dictan otras disposiciones (11 de junio de 1998).

Colombia, Congreso de la República. Ley 909/2004 Por la cual se expiden normas que regulan el Empleo Público, la Carrera Administrativa, la Gerencia Pública y se dictan otras disposiciones (23 de septiembre de 2004).

Colombia, Congreso de la República. Ley 1033/06 por la cual se establece la Carrera Administrativa Especial para los Empleados Públicos no uniformados al servicio del Ministerio de Defensa Nacional (19 de julio de 2006).

Colombia, Congreso de la República. Acto Legislativo 01 de 2008 (26 de diciembre de 2008).

Colombia. Congreso de la República. Acto Legislativo 04 de 2011 (7 de julio de 2011).

Colombia, Corte Constitucional. Sentencia C-391 de 1993 (16 de septiembre de 1993).

Colombia, Corte Constitucional. Sentencia C-356 de 1994 (11 de agosto de 1994).

Colombia, Corte Constitucional. Sentencia C-040 de 1995 (9 de febrero de 1995).

Colombia, Corte Constitucional. Sentencia C-041 de 1995 (9 de febrero de 1995).

Colombia, Corte Constitucional. Sentencia C-317 de 1995 (19 de julio de 1995). 
Colombia, Corte Constitucional. Sentencia C-306 de 1995 (13 de julio de 1995). Colombia, Corte Constitucional. Sentencia C-037 de 1996 (5 de febrero de 1996). Colombia, Corte Constitucional. Sentencia C-562 de 1996 (24 de octubre de 1996).

Colombia, Corte Constitucional. Sentencia C-030 de 1997 (30 de enero de 1997). Colombia, Corte Constitucional. Sentencia C-408 de 1997 (28 de agosto de 1997).

Colombia, Corte Constitucional. Sentencia C-372 de 1999 (26 de mayo de 1999).

Colombia, Corte Constitucional. Sentencia C-371 de 2000 (29 de marzo de 2000).

Colombia, Corte Constitucional. Sentencia C-808 de 2001 (1 de agosto de 2001).

Colombia, Corte Constitucional. Sentencia C-714 de 2002 (3 de septiembre de 2002).

Colombia, Corte Constitucional. Sentencia C- 074 de 2004 (3 de febrero de 2004).

Colombia, Corte Constitucional. Sentencia C-733 de 2005 ( 14 de julio de 2005).

Colombia, Corte Constitucional. Sentencia C-211 de 2007 (21 de marzo de 2007).

Colombia, Corte Constitucional. Sentencia C-588 de 2009 (27 de agosto de 2009).

Colombia, Corte Constitucional. Sentencia C- 249 de 2012 (29 de marzo de 2012).

Colombia, Presidencia de la República. Decreto 1222/93 Por el cual se desarrollan los numerales 3 y 4 del artículo 29 de la Ley 27 de 1992 (28 de junio de 1993).

Colombia, Presidencia de la República. Decreto 1224/93 por el cual se reglamentaron los artículos 18 y 20 de la Ley 27/92 sobre la aplicación por primera vez de la carrera administrativa en las entidades territoriales.

Colombia, Presidencia de la República. Decreto de Ley 770 de 2005 por el cual se establece el sistema de funciones y de requisitos generales para los empleos públicos del Orden Nacional (19 de marzo de 2005).

Constitución Política de Colombia de 1886. (2. ${ }^{a}$ Ed. 1990). Bogotá: Ministerio de Gobierno.

Constitución Política de Colombia de 1991 [Anotada por Francisco Gómez Sierral. (31. ${ }^{a}$ Ed. 2013). Bogotá: Leyer.

Instituto Colombiano de Cultura (1973). El pensamiento político de Rafael Uribe Uribe. Bogotá: Instituto Colombiano de Cultura.

Olías de Lima, B. (1995). La Gestión de Recursos Humanos en las Administraciones Públicas. Madrid: Universidad Complutense. 
Parada Vásquez, R. (1995). Derecho Administrativo. Madrid: Marcial Pons.

Puentes González, G. (2004). "La carrera administrativa: ¿Anhelo o realidad?". Revista Desafíos, 11, 60-105.

Pomer, L. (2004). La corrupción una cultura argentina. Buenos Aires. Editorial Leviatán.

Robinson, J. E Acemoglu, D. (2012). Por qué Fracasan los países.Bogotá: Deusto y Planeta Colombiana

Rodríguez, L. (2002). Derecho Administrativo: General y Colombiano. Bogotá: Editorial Temis.

Rose, R. (1998). El Gran Gobierno, un acercamiento desde los programas gubernamentales. México: Fondo de Cultura Económica.

Salom Becerra, A. (1988). Un tal Bernabé Bernal. Bogotá: Tercer Mundo Editores.

Shafritz J. E Hyde A. (1999) Clásicos de la Administración Pública. México: Fondo de Cultura Económica.

Wasserman, M. (19 de marzo de 2015). El olvidado servidor público. El Tiempo. Recuperado de http://www.eltiempo.com/opinion/columnistas/el-olvidadoservidor-publico-moises-wasserman-columnista-el-tiempo/15429297

Weber, M. (1985). ¿Qué es la burocracia? Buenos Aires: Editorial Leviatán. 